\title{
The Mediating Effect of Social Networks on the Influence of Tacit Knowledge on Organizational Learning and the Attendant Impact on Competitive Advantage: Learning from the ICT Content Service Providers Sector in Kenya
}

\author{
John Muigai Mucai \\ $\mathrm{PhD}$ Graduate \\ School of Business \\ University of Nairobi, Kenya \\ Evans Aosa \\ Professor of Strategy \\ School of Business \\ University of Nairobi, Kenya \\ Zachary Bolo Awino \\ Professor of Strategy and Supply Chain \\ School of Business \\ University of Nairobi, Kenya \\ James Njihia Muranga \\ Associate Professor of Strategic Information Systems \\ School of Business \\ University of Nairobi, Kenya
}

\begin{abstract}
Social networks are at the heart of human interactions in organizations. Such interactions entail a continuous interchange of explicit and tacit knowledge, resulting in organizational learning; with the attendant positive impact on organizational performance and competitiveness. Scholars have studied different aspects ofthis phenomenon. The current study, using data gathered from 135 ICT content providers based in Nairobi licensed by the Communication Authority of Kenya, adds to the repository of strategic management knowledge by providing empirical evidence showing that social networks have a mediating effect on the influence of tacit knowledge on organizational learning. Further, that organizational learning itself mediates the effect of tacit knowledge on competitive advantage.
\end{abstract}

Keywords: Social Networks Theory, Resource-Based View, Knowledge-Based View, Organizational Learning Theory

\section{Introduction}

The desire for individuals to belong to social networks is inherent in human nature. Almost all interactions between people can be thought of in the context of a social network of one form or another (Kadushin, 2012). As stated by the Greek philosopher Aristotle in the $4^{\text {th }}$ Century BC, nature has implanted a social instinct in every human being and anyone who is not able to live in society, or who believes that he is self-sufficient "must be either a beast or a god" (as cited in Butler,1886, p.113).

In an organizational context, social networks are an important means through which knowledge is disseminated. The repetitive actions by individuals in the organization, and their continuous interaction with one another transform knowledge into products and services (Guyo, 2012; Kogut \& Zander, 1992). It is not the people that one hires that are the assets; it is the relationships that they bring to the firm that add real value. These relationships and intellectual capital, of which tacit knowledge is a part, are intrinsically linked and contribute to a firm's competitiveness (Kamukama, 2013). Networks that facilitate knowledge transfer among people in a firm provide opportunities for learning and cooperation (Janhonen \& Johanson, 2011). 
Collaboration through social networks allows individuals in teams to use shared knowledge effectively for the betterment of the firm, with employees attaining the dual benefit of individual and team accomplishment. Social networks provide the context through which the sharing of knowledge occurs in a continuous individual and organizational learning process that enhances the competitive advantage of the organization (Nonaka, 1994; Shilke, 2014).

Social networks evolve from individual members in an organization interacting with one another, as well as with other people outside the organization; and in the process producing extended network structures. These interactions take place within the context of the social status of the individuals and the institutions to which they belong (Kadushin, 2012). Social networks are key organizational structures for sharing of knowledge in teams and workgroups (Bosua \& Scheepers, 2007). Evans et al. (2013) describe social networks as the set of people with whom individuals working in an organization interact. This includes other employees, customers, suppliers, family members and other social groupings. An individual's free will in decision-making is limited by influences of their social setting. In other words, the individual becomes less of a principal and more of an agent considering the norms of the profession to which he belongs, the organization of which he is a member, and his cultural background; as well as his or her religious background. Because of this, knowledge acquisition and transfer by an individual must be considered in the wider context of the social setting of which the individual works as its agent (Bartlet \& Ghoshal, 2013).

Organizational learning occurs when new tacit and explicit knowledge is developed based on the on-going experiences of individuals in the organization. Further, organizational learning can potentially influence behaviors and improve the capabilities of the organization (Jiménez-Jiménez \& Sanz-Valle, 2011. It can also be viewed as the change that occurs in accumulated knowledge of an organization as the organization gains experience. It takes place through individuals. It entails continuous validation and transformation of experiences into knowledge that is valuable to the organization (Argote, 1999; Argyris \& Schön, 1978; Nonaka, 1994; Namada, 2013; Nzuve \& Omolo, 2012).

Competitive advantage, on the other hand, is a firm's unique position relative to its competitors. It is an attribute or combination of attributes such as a physical resource or an intangible resource that enables an organization to perform better than its rivals. Sustainable competitive advantage is also a function of the extent to which the firm is able to prevent entry of new players in that industry, threats of substitute products or services, and competition between existing players in the industry; the power exerted by suppliers in the industry, and the power possessed by buyers in that industry (Porter, 2008; Ogutu \& Nyatichi, 2012).

The main objective of the current study was to determine how social networks affect the influence of tacit knowledge on organizational learning, and the attendant impact on competitive advantage. The study domain was the ICT sector in Kenya. This sector has been growing rapidly in recent years, opening up new avenues for knowledge creation and dissemination. It contributes about $1.7 \%$ to the Gross Domestic Product of the country; and is critical to the government's objective of achieving rapid modernization and growth of the economy (Communications Authority of Kenya, 2015; Kenya National Bureau of Standards, 2018).

\section{Materials}

The main theories that underlie the relationship between tacit knowledge, social networks, organizational learning, and competitive advantage are the Resource Based View, Knowledge Based View, and Organizational Learning Theory; and Social Networks Theory. Competitive advantage is a relative notion and is embedded in all these theories. It refers to superior performance of a firm compared to its peers in the same industry or relative to the industry average; and is dependent on the contextual setting under consideration (Nonaka, 1994; Nonaka \& Krogh, 2009; Raduan, Jegak, Haslinda, \& Alimin, 2009; Teece, Pisano \& Shuen, 1997).

The Resource-Based View has its roots in evolutionary economics theory. This theory looks at competitive advantage from the "inside-out". In other words, the firm is considered to be a bundle of resources and competitive advantage is sustained by nurturing opportunities inherent in the internally endowed resources. Unlike in the Porter (2008) model where the industry takes center stage, "the outside-in-model", in the Resource Based View, the firm is the central unit of analysis and competitive advantage is said to be dependent on four key attributes of a firm's resources: namely, how valuable they are, their rarity, their un-substitutability, and their inimitability (Barney, 1991; Kamukama, 2013). 
The Knowledge-Based View extends the ideas of the Resource-Based Viewand postulates that knowledge is a special resource that is at the heart of a firm. Further, that knowledge is heterogeneous, cannot be easily imitated by others outside the firm, and is therefore a source of competitive advantage. The Knowledge-Based View considers knowledge as a resource that is of strategic importance to a firm. Further, that because knowledge, especially tacit knowledge possessed by individuals in a firm, is complex and difficult for others to copy, it creates a competitive advantage (Polanyi, 1966; Cheruiyot, Jagongo,\& Owino, 2012; Nonaka \& Krogh, 2009), a key focus of the current study.

The emergence of ideas around the Social Networks Theory can be attributed to social economists who introduced the term social capital to describe social relationships between individuals that translate into the creation of economic value (Smedlund, 2008). Smedlund argues that the idea of social capital can be equated to the notion of informal organization that exists in a firm, an organizational arrangement that is not necessarily aligned with the formal organizational hierarchy of the firm. Smedlund proposes that social networks are germane to social capital, and follow the logic of the economic theory of increasing returns. In other words, as more and more actors join the social network, the network simultaneously continues to grow stronger and adds value to the individuals in it; as well as to the organization in which they belong. Smedlund further argues that tacit knowledge is an inherent aspect of social networks, and that strong links amongst people in a network creates trust and commitment which in turn facilitates easier communications between the network participants.

The transfer of tacit knowledge within a social network is dependent on the relationships between individuals in the network. An awareness of how individuals share knowledge is key to the understanding of the workings of social networks. It can clarify the position of individuals as actors within a network and the implications of this on access to information, and how this ultimately affects organizational performance (Evans et al., 2013). In some industries, such as the hyper-competitive biotechnology industry, where there is rapid knowledge creation and obsolescence, formation of social networks is one of the most efficient tools for diffusion of tacit knowledge that manifests itself as organizational learning that ultimately creates competitive advantage (Grant, 1999; Liebeskind, Oliver, Zucker, \& Brewer, 1995).

The Organizational Learning Theory has its roots in the behavioral theory of the firm pioneered by Cyert and March (1963). The key postulate of the theory is that as individuals within an organization learn, the organization itself learns too. The knowledge generated by individuals is embedded in the mainstream of organizational processes and translates into improvements in the performance of the organization. It is the process through which an organization eventually accomplishes the ideal of becoming a learning organization (Argote, 1999;Namada, 2013; Serrat, 2017).

Several studies have been done in the recent past examining different aspects of the relationship between tacit knowledge, social networks, organizational learning; and competitive advantage. Examples include the study by Janhonnen and Johanson (2011). This study focused primarily on knowledge creation, knowledge diffusion, and social networks in the context of teams, but did not examine how these constructs influenced the competitiveness of the organizations that were covered by the study. A study by Hau, Kim, Lee, and Kim (2013) involving 2,010 employees in seven firms in Korea looked at how motivations of individuals and social capital affect their intensions of sharing tacit knowledge. The study found that social capital and intension to share tacit knowledge were positively correlated. However, the study did not look at how these two variables interplayed with organizational learning; and the related effects on competitive advantage. The results of a research study in Ireland covering 48 teams in 46 small and medium-sized software development firms supported the hypothesis that the tacit knowledge possessed by a team is generated to a certain extent through the frequency of social interactions, which in turn improves the competiveness of the firm (Ryan \& Lero, 2012). Munjuri (2013), in a study covering 54 licensed banks and insurance firms in Kenya, established that social capital, together with employee empowerment mediates the relationship between human capital on firm performance. Social capital, in this context, was defined as the actual and potential resources that an individual enjoys by virtue of the network of relationships that they possess. Empirical evidence from the study showed that social networks provided the necessary traction for tacit knowledge to translate into a competitive advantage for the organization. These findings seemed to resonate with the views of Ding et al. (2015) that sharing of tacit knowledge is a highly personal cognitive process that occurs in an environment characterized by trust, respect and reciprocity. However, the study did not explicitly test the organizational learning that emerges from tacit knowledge sharing. 
In addition to the gaps in empirical research examples of which are presented above, it is evident from the existing literature that there is an unsettled debate amongst scholars on the operationalization of the tacit knowledge construct (Ambrosini \& Bowman, 2001; Buunk, 2017; Donaldson, 2001; Gourlay, 2004; Gourlay, 2006; Huysman \& Wulf, 2006; Leonard \& Sensiper, 1998; Ngah, \& Jusoff, 2009; Polanyi, 1996; Spender 1996;Taylor, 2007; Tsoukas, 2009; Tsoukas, 2015; Wagner \&Sternberg, 1985). A similar state of affairs prevails with respect to the competitive advantage construct (Barnes, 1954; Nonaka, 1994; Nonaka \& Krogh, 2009; Raduan, Jegak, Haslinda, \& Alimin, 2009; Sigalas, Economou, \& Georgopoulos, 2013; Teece, Pisano \& Shuen, 1997; Turner, 2009). These challenges probably explain the apparent dearth of empirical studies on the relationship between tacit knowledge and competitive advantage despite the considerable amount of related conceptual strategic management literature. There appears to be better alignment amongst scholars regarding operationalization of the social networks and organizational learning constructs (Collins, 2003; Lloria \& MorenLuzon, 2014; Namada, 2013).

The current study was motivated by a desire to contribute in filling some of the gaps in empirical research; and was guided by one pertinent question. To what extent do social networks mediate the influence of tacit knowledge on organizational learning, and does organizational learning itself amplify the direct effect of tacit knowledge on competitive advantage?

\section{Methods and Results}

The research followed a post-positivist critical realism philosophical orientation, using a cross-sectional survey. By following a positivistic approach, quantitative data was elicited from study participants using a selfadministered survey instrument. The key research variables were evaluated using proxy indicators of each variable, with an allowance for measurement errors, in line with the post-positivist critical realism paradigm. The population for the study was the 197 ICT content service providers based in Nairobi licensed by the Communications Authority of Kenya (2015). Valid feedback was received from 135 firms, representing a response rate of $69 \%$ which was within the required sample size threshold.

Data was sought from three managers from each of the firms under study namely, the Strategic Planning Manager, the ICT Manager, and the Human Resources Manager. In instances where these positions were not in existence or the managers were unavailable, feedback to the survey was solicited from other managers holding different titles but performing equally senior functions in the organization. Sample bias homogeneity of variance tests were performed using One-Way ANOVA to confirm that there were no significant differences in the way that the different categories of managers responded to the questionnaire.

The research hypotheses that were tested in the study were as follows:

$\mathbf{H}_{01}$ : Social networks do not mediate the influence of tacit knowledge on organizational learning

$\mathbf{H}_{1}$ : Social networks mediate the influence of tacit knowledge on organizational learning

$\mathbf{H}_{\mathbf{0 2}}$ : Organizational learning does not mediate the influence of tacit knowledge on competitive advantage

$\mathbf{H}_{2}$ : Organizational learning mediates the influence of tacit knowledge on competitive advantage

The quality of an empirical study depends to a large extent on the choice of measures used to operationalize the study variables and how these measures align with the circumstances of the study (Cooper \& Schindler, 2006). The challenge of choosing the right measures is magnified when one is dealing with abstract concepts, such as the ones applicable in the current study (Zikmund, Babin, Carr,\& Griffin, 2010). Because of this, multiple indicators of the latent variables for the current study were used, closely aligned with indicators used in prior empirical studies, in order to obtain reasonably accurate representations of the underlying concepts (Awino, 2013; Collins 2003; Lloria \& Moren-Luzon, 2014; Namada, 2013; Rashid, Hassan,\& Al-Oqaily, 2015; Yang \& Farn, 2010). The four constructs in the conceptual model that guided the empirical study were tacit knowledge, organizational learning, social networks, and competitive advantage.

The mediating effect of social networks in the context of the overall hypothesized model,which also includes the direct effect of tacit knowledge on competitive advantage with organizational learning as a mediator of this relationship, was tested using the SmartPLS data analysis tool(Ringle, Wende \& Becker, 2015). The mediating effect of organizational learning on the relationship between tacit knowledge and competitive advantage in the context of the overall hypothesized model, was also tested using the SmartPLS too. These tests were done in two 
stages. Firstly, indicators of all the first order constructs were used to generate factor scores for the first order constructs. Secondly, the first order factor scores were used as indicators of the second order constructs.

Latent variables of the second order constructs were then generated from SmartPLS and used to run the PLS algorithm and bootstrapping. The bootstrapping algorithm was run in SmartPLS using 5,000 sub-samples. Figure 1 shows a structural model extracted from SmartPLS reflecting the four hypothesized latent variables and their interrelationships. Table1 contains various pertinent indicators generated from SmartPLS in respect of the relationship between the four constructs tacit knowledge (TKW), social networks (SNW), and organizational learning (ORG); and competitive advantage (CAD).

Table1: Indicators of the Relationships between TKW, SNW, OGL, and CAD

\begin{tabular}{llccrr}
\hline Description & Path Model & $\begin{array}{c}\text { Original } \\
\text { Sample } \\
(\mathrm{O})\end{array}$ & $\begin{array}{c}\text { Standard } \\
\text { Deviation } \\
(\text { STDEV })\end{array}$ & $\begin{array}{r}\text { T Statistics } \\
\mid \text { O/STDEV|) }\end{array}$ & $\begin{array}{c}\text { P } \\
\text { Values }\end{array}$ \\
\hline Total & ORG -> CAD & 0.723 & 0.050 & 14.553 & 0.000 \\
Effects & SNW -> CAD & 0.359 & 0.045 & 7.917 & 0.000 \\
& SNW -> ORG & 0.496 & 0.053 & 9.336 & 0.000 \\
& TKW -> CAD & 0.626 & 0.064 & 9.726 & 0.000 \\
& TKW -> ORG & 0.585 & 0.071 & 8.216 & 0.000 \\
& TKW -> SNW & 0.284 & 0.073 & 3.899 & 0.000 \\
\hline Specific & TKW -> SNW -> ORG -> & & & & \\
Indirect & CAD & 0.102 & 0.027 & 3.789 & 0.000 \\
Effects & TKW -> ORG -> CAD & 0.321 & 0.052 & 6.150 & 0.000 \\
& TKW -> SNW -> ORG & 0.141 & 0.036 & 3.882 & 0.000 \\
\hline f-square & ORG -> CAD & 1.305 & 0.362 & 3.607 & 0.000 \\
& SNW -> ORG & 0.524 & 0.138 & 3.788 & 0.000 \\
& TKW -> CAD & 0.103 & 0.050 & 2.056 & 0.040 \\
& TKW -> ORG & 0.419 & 0.182 & 2.308 & 0.021 \\
& TKW -> SNW & 0.088 & 0.051 & 1.725 & 0.085 \\
\hline HTMT & ORG -> CAD & 0.842 & 0.028 & 29.856 & 0.000 \\
& SNW -> CAD & 0.447 & 0.058 & 7.696 & 0.000 \\
& SNW -> ORG & 0.622 & 0.044 & 14.098 & 0.000 \\
& TKW -> CAD & 0.626 & 0.064 & 9.726 & 0.000 \\
& TKW -> ORG & 0.585 & 0.071 & 8.216 & 0.000 \\
& TKW -> SNW & 0.284 & 0.073 & 3.899 & 0.000 \\
\hline SRMR & Estimated Model & 0.019 & 0.006 & 3.216 & 0.001 \\
\hline R Square & CAD & 0.736 & 0.042 & 17.637 & 0.000 \\
& ORG & 0.568 & 0.572 & 0.058 & 9.857 \\
& SNW & 0.081 & 0.085 & 0.041 & 1.968 \\
\hline
\end{tabular}

Note. TKW = Tacit Knowledge; SNW = Social Networks; OGL = Organizational Learning; CAD = Competitive Advantage; HTMT = Heterotrait-Monotrait Ratio

Source: Research data, 2018

The Heterotrait-Monotrait Ratios (HTMT) for all the relationships between the constructs were below the .90 threshold. The p-values for all the ratios were below .05 whilst the related t-statistics were above 1.96 (2-tailed) suggesting that there was discriminant validity between the constructs. The SRMR ratio for the model was .019 which was below the recommended threshold of .08 indicating good model fit (Gaskin \& Lim, 2016; Henseler, Ringle \& Sarstedt, 2015).

The test results showed that social networks did indeed mediate the effect of social networks on organizational learning. The specific indirect effect was $.141(\mathrm{p}$-value $=.000 ; \mathrm{t}$-statistic $=3.882)$. Accordingly, the null hypothesis $\left(\mathbf{H}_{\mathbf{0 1}}\right)$ that social networks in an organization do not have a mediating effect on the influence of tacit knowledge on organizational learning was rejected, and the alternative hypothesis $\left(\mathbf{H}_{\mathbf{1}}\right)$ that social networks in an organization have a mediating effect on the influence of tacit knowledge on organizational learning was accepted. 
The specific indirect effect of organizational learning on the influence of tacit knowledge on competitive advantage was $.321(\mathrm{p}$-value $=.000 ; \mathrm{t}$-statistic $=6.150)$.

The indirect effect was significant based on the .05 level of significance and the 1.96 threshold for t-statistics (2tailed). This meant that the specific indirect effect of organizational learning on the relationship between tacit knowledge and competitive advantage was statistically significant. Accordingly, the null hypothesis $\left(\mathbf{H}_{\mathbf{0 2}}\right)$ that organizational learning does not have a mediating effect on the influence of tacit knowledge on competitive advantage was rejected, and the alternative hypothesis $\left(\mathbf{H}_{\mathbf{2}}\right)$ that organizational learning has a mediating effect on the influence of tacit knowledge on competitive advantage accepted.

\section{Conclusion}

The study showed that whilst the primary mediator of the influence of tacit knowledge on competitive advantage is organizational learning, social networks effectively enhance this mediation process. The plausibility of this notion is apparent when one considers that organizational learning processes by their nature entail interaction between people in an organization, for example through best practice sharing or through knowledge sharing in work groups. With this in mind, it makes sense that the social networks, operationalized in the current study as the frequency and closeness of interactions between employees and internal and external contacts; and internal network building practices, would enhance the effectiveness of the organizational learning processes.

\section{Implications of the Study}

The study is an additional building block in strategic management theory, backed by empirical evidence, on the mediating effect of social networks in the diffusion of tacit knowledge into organizational learning; as well as the strong mediating effect of organizational learning on the influence of tacit knowledge on competitive advantage. It can be discerned from the study that social networks are important in the diffusion of tacit knowledge and enhancement of organizational learning; a fact that should be given due consideration by policy makers and strategic management practitioners. The strong mediating effect of organizational learning in enhancing the influence of tacit knowledge as a driver of organizational competitiveness means that leaders should strive to develop and nurture an organization learning culture in their respective organizations. This would include developing robust talent acquisition, talent development and talent retention policies; promoting a tacit knowledge culture that includes teamwork, mentoring, and best practice sharing.

\section{References}

Ambrosini, V., \& Bowman, C. (2009). What are dynamic capabilities and are they a useful construct in strategic management? International Journal of Management Reviews, 11(1), 29-49.

Argyris, C. \& Schön, D.A. (1978). Organizational learning: A theory of action perspective. Reading, MA: Addison-Wesley.

Argote, L. (1999). Organizational learning: Creating, retaining and transferring knowledge. Norwell, MA: Kluwer Academic Publishers.

Awino, Z.A. (2013). Strategic planning and competitive advantage of ICT small and medium enterprises in Kenya. Business and Management Horizons, 1 (1), 191-204.

Barnes, J. (1954). Class and committees in a Norwegian island parish. Human Relations, 7, 39-58.

Barney, J.B. (1991). Firm resources and sustained competitive advantage. Journal of Management, 17 (1), 99 120.

Bartlet, C.A. \& Ghoshal, S. (2013). Building competitive advantage through people. Sloan Management Review, 43 (2).

Bosua, R., \& Scheepers, R. (2007). Towards a model to explain knowledge sharing in complex organizational environments. Knowledge Management Research \& Practice, 5(2), 93-109.

Butler, N. M., \& Jowett, B. (1886). The Politics of Aristotle. Political Science Quarterly, 1(1), 146.

Buunk, I., Hall, H. \& Smith, C. (2017). Tacit knowledge sharing and social media: the determination of a methodological approach to explore the intangible. In Proceedings of ISIC, the Information Behaviour Conference, Zadar, Croatia, 20-23 September, 2016: Part 2. Information Research, 22(1), paper isics1606). Retrieved from http://InformationR.net/ir/22-1/isic/isics1606.html (Archived by WebCite® at http://www.webcitation.org/6oW4iu6mu) 
Cheruiyot, C.K., Jagongo, A. \& Owino, E.O. (2012). Institutionalization of knowledge management in manufacturing enterprises in Kenya: A case of selected enterprises. International Journal of Business and Social Science, 3 (10), 127- 138.

Collins, C.J. \& Clark, K.D. (2003). Strategic human resource practices, top management team social networks, and firm performance: The role of human resource practices in creating organizational competitive advantage. Academy of Management Journal, 45(5), 740-751.

Communications Authority of Kenya (2015). First Quarter Sector Statistics Report for the Financial Year 2015/16 (July-September 2015). Retrieved from http://www.ca.go.ke.

Cooper, D.R. \& Schindler, P.S. (2006). Business research methods. Irwin: McGraw-Hill.

Cyert, R. M. \& March, J. G. (1963). A behavioral theory of the firm. Englewood Cliffs: Prentice Hall.

Ding, C.Q., Xue, J. \& Yuan, J. (2015). Research on tacit knowledge-sharing willingness in trust perspective: Empirical analysis on communication enterprises. Paper presented at International Conference of Electrical, Automation and Mechanical Engineering (EAME 2015), Phuket, Thailand.

Donaldson, L. (2001) Reflections on knowledge and knowledge-intensive firms. Human Relations, 54, 955-963.

Evans, N., Bosua, R. \& Sawyer, J. (2013). Using social networks for knowledge acquisition in regional Australian SMEs: Management considerations. Journal of Knowledge Management Practice, 14 (2).

Gaskin, J. \& Lim, J. (2016). Master validity tool, AMOS plugin. Retrieved from http://statwiki.kolobkreations.com.

Gourlay, S. (2004). Tacit knowledge: The variety of meanings in empirical research. SSRN Electronic Journal. Retrieved from https://papers.ssrn.com/sol3/papers.cfm?abstract_id=676466

Gourlay, S. (2006). Towards conceptual clarity for 'tacit knowledge': A review of empirical studies. Knowledge Management Research \& Practice, 4(1), 60-69.

Grant, R. (1999). Prospering in dynamically-competitive environments: Organizational capability as knowledge integration. Knowledge and Strategy, 133-153.

Guyo, W. (2012). The role of HRM in intra-firm operationalization of tacit knowledge in Kenyan state corporations. (Unpublished doctoral thesis). Jomo Kenyatta University of Agriculture and Technology, Nairobi, Kenya.

Hau, Y. S., Kim, B., Lee, H., \& Kim, Y. G. (2013). The effects of individual motivations and social capital on employees' tacit and explicit knowledge sharing intentions. International Journal of Information Management, 33(2), 356-366.

Henseler, J., Ringle, C.M. and Sarstedt, M. (2012). Using partial least squares path modeling in international advertising research: Basic concepts and recent issues, in Okazaki, S. (Ed.), Handbook of Research in International Advertising. Cheltenham: Edward Elgar Publishing

Huysman, M. \& Wulf, V. (2006). IT to support knowledge sharing in communities, towards a social capital analysis. Journal of Information Technology, 21(1), 40-51.

Janhonen, M. \& Johanson, J. (2011). The role of knowledge conversion and social networks in team performance. International Journal of Information Management, 31, 217-225.

Jiménez-Jiménez, D. \& Sanz-Valle, R. (2011). Innovation, organizational learning, and performance. Journal of Business Research, 64, 408-417.

Kamukama, N. (2013). Intellectual capital: Company's invisible source of competitive advantage. Competitiveness Review: An International Business Journal, 23 (3), 260-283.

Kadushin, C. (2012). Understanding social networks: Theories, concepts, and findings. New York: Oxford University Press.

Kenya National Bureau of Standards (2018). Quarterly Gross Domestic Product Report, Second Quarter, 2018. Retrieved from https://www.knbs.or.ke/data-releases/

Kogut, B. \& Zander, U. (1992). Knowledge of the firm, combinative capabilities, and the replication of technology. Organization Science, 3 (3), 383-397.

Leonard, D., \& Sensiper, S. (1998). The Role of Tacit Knowledge in Group Innovation. California Management Review, 40(3), 112-132.

Liebeskind, J. P., Oliver, A. L., Zucker, L., \& Brewer, M. (1995). Social Networks, Learning, and Flexibility: Sourcing Scientific Knowledge in New Biotechnology Firms. ISSR Working Papers in Social Sciences, 6(4), 7994-95. 
Lloria, B.M. \& Moreno-Luzon, M. (2014). Organizational learning: Proposal of an integrative scale and research instrument. Journal of Business Research, 67, 692-697.

Munjuri, M. (2013). Human capital, social capital, employee empowerment, quality of decisions and performance of commercial banks and insurance firms in Kenya. (Doctoral thesis, University of Nairobi, Nairobi, Kenya). Retrieved from http://erepository.uon.ac.ke.

Namada, J.M. (2013). Strategic planning systems, organizational learning, strategy implementation and performance of firms in Export Processing Zones in Kenya. (Doctoral thesis, University of Nairobi, Nairobi, Kenya). Retrieved from http://erepository.uon.ac.ke.

Ngah, R. \& Jusoff, K. (2009). Tacit knowledge sharing and SMEs' organizational performance. International Journal of Economics and Finance, 1(1), 216-220.

Nonaka, T. (1994). A dynamic theory of organizational knowledge creation. Organizational Science, 5 (1), 14-37.

Nonaka, T. \& Krogh, G. (2009). Tacit knowledge and knowledge conversion: Controversy and advancement in organizational knowledge creation theory. Organizational Science, 20 (3), 635-652.

Nzuve, S.N.M. \& Omolo, E.A. (2012). A study of the practice of the learning organization and its relationship to performance among Kenyan commercial banks. Problems of Management in the 21st Century, 4, 45-55.

Ogutu, M. \& Nyatichi, V. (2012). Competitive strategies adopted by multinational banks in Kenya. DBA Africa Management Review, 2 (1), 98-109.

Polanyi, M. (1966). The tacit dimension. Chicago: University of Chicago Press.

Porter, M. E. (2008). The five competitive forces that shape strategy. Harvard Business Review, 24-40.

Raduan, C. R., Jegak, U., Haslinda, A. \& Alimin, I. I. (2009). A conceptual framework of the relationship between organizational resources, capabilities, systems, competitive advantage and performance. Research Journal of International Studies, 12, 45-58

Rashid, A.M., Hassan, Z.B. \& Al-Oqaily, A.T. (2015). Investigation of tacit knowledge measurement methods. Journal of Theoretical \& Applied Information Technology, 76(2), 170-177.

Ringle, C. M., Wende, S., and Becker, J.M. (2015). SmartPLS 3. Boenningstedt: SmartPLS GmbH. Retrieved from http://www.smartpls.com.

Ryan, S. \& Lero, R.V.O. (2012). Social interaction, team tacit knowledge and transactive memory: Empirical support for the agile approach. In: Researching Agile Development of Information Systems (RAISE) Conference, 11 Oct 2012, London, UK.

Serrat O. (2017). A primer on organizational learning. In: Knowledge Solutions. Singapore: Springer.

Sigalas, C., Economou, V.P. \& Georgopoulos, N.B. (2013). Developing a measure of competitive advantage. Journal of Strategy and Management, 6(4), 320-342

Smedlund, A. (2008). The knowledge system of a firm: Social capital for explicit, tacit and potential knowledge. Journal of Knowledge Management, 12(10), 63-77.

Spender, J.-C. (1996). Competitive advantage from tacit knowledge? Unpacking the concept and its strategic implication. In: Moingeon, B. and Edondson, A., (Eds.). Organizational Learning and Competitive Advantage, pp. 56-73. London \& Thousand Oaks: Sage

Taylor, H. (2007). Tacit knowledge. International Journal of Knowledge Management, 3(3), 60-73.

Teece, D., Pisano, G., \& Shuen, A. (1997). Dynamic capabilities and strategic management "dynamic capabilities and strategic management". Strategic Management Journal, 18(7), 509-533.

Tsoukas, H. (2015). How Should We Understand Tacit Knowledge? A Phenomenological View. Handbook of Organizational Learning and Knowledge Management, 453-476.

Tsoukas, H. (2009). A dialogical approach to the creation of new knowledge in organizations. Organization Science, 20(6), 941-957

Turner, B. S. (2009). The new Blackwell companion to social theory. Chichester, U.K.: Wiley-Blackwell.

Wagner, R.K. and Sternberg, R.J. (1985). Practical intelligence in real-world pursuits: the role of tacit knowledge. Journal of Personality and Social Psychology, 49, 436-458.

Yang, S. \& Farn, C. (2010). Investigating tacit knowledge acquisition and sharing from the perspective of social relationships-A multilevel model. Asia Pacific Management Review, 15(2), 167-185.

Zikmund, W.G., Babin, B.J., Carr, J.C., \& Griffin, M. (2010). Business research methods (8th Ed). Mason: Cengage Learning. 


\section{Appendix}

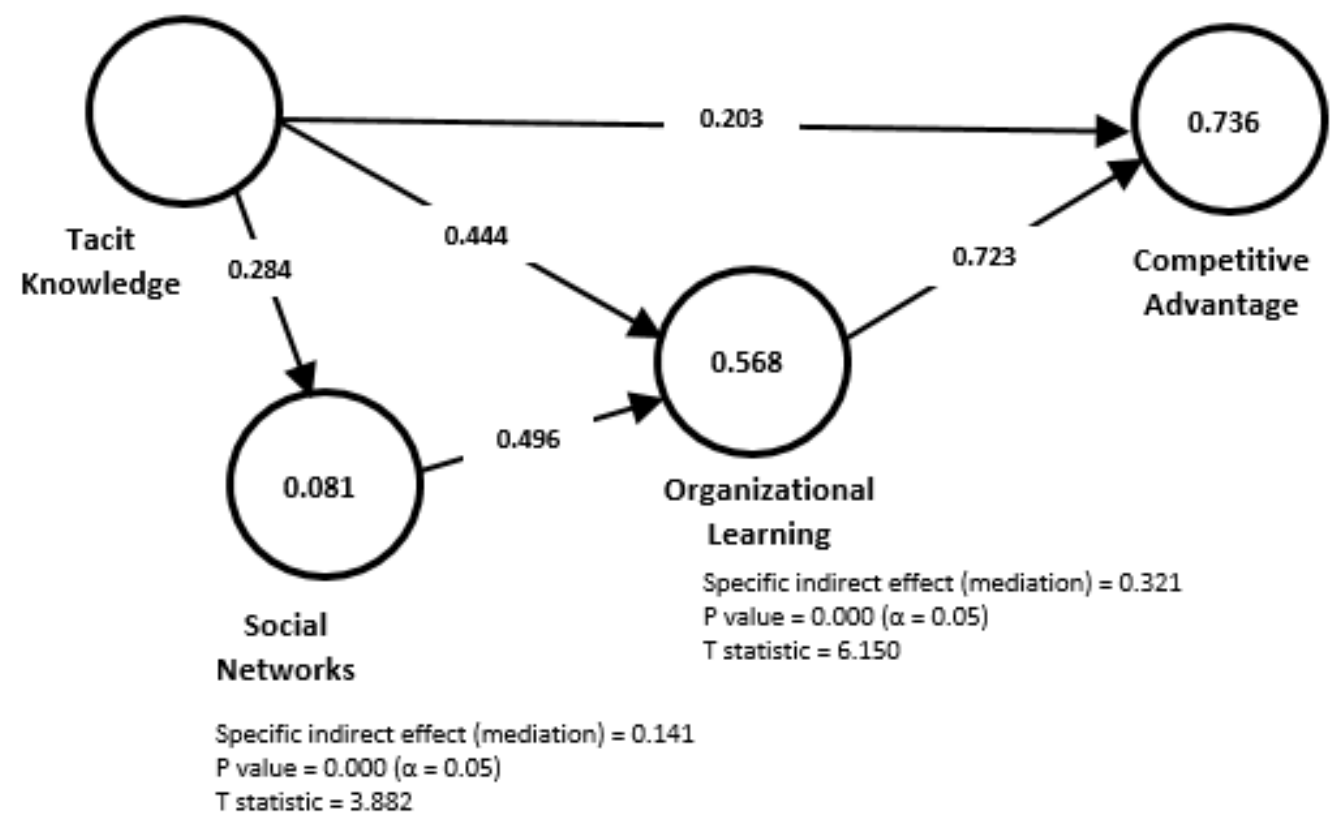

Figure 1. Structural model showing relationship between tacit knowledge, organizational learning, social networks and competitive advantage

Note: Numbers inside ellipses are $\mathrm{R}^{2}$ and numbers on the arrows are standardized coefficients

Source: Research data, 2018 